\title{
Downward Ocular Deviation
}

National Cancer Institute

\section{Source}

National Cancer Institute. Downward Ocular Deviation. NCI Thesaurus. Code C42086.

Vertical strabismus in which there is permanent downward deviation of the visual axis of one eye. 